\title{
CHAPTER 26 \\ SURGICAL INTERVENTIONS FOR CLUSTER HEADACHE, INCLUDING IMPLANTED STIMULATORS
}

\author{
Koen Paemeleire and Paolo Marteletti
}

Prof. Dr. Koen Paemeleire

Department of Neurology

Ghent University Hospital

De Pintelaan 185, B-9000 Ghent, Belgium

$\mathrm{T}+3293324529$

$F+3293324971$

E koen.paemeleire@Ugent.be

Prof. Dr. Paolo Martelletti

Department of Medical and Molecular Sciences

$2^{\text {nd }}$ School of Medicine and Surgery

Sapienza University of Rome

Sant'Andrea Hospital

Via di Grottarossa 1035, I-00189 Rome, Italy

$\mathrm{T}+390633776778$

$F+390633775323$

Epaolo.martelletti@uniroma1.it 


\section{Abstract}

Refractory cluster headache is one of the most devastating conditions known to man.

Historically, only destructive procedures were available for these desperate patients in which all drug therapies failed. The surgical interventions were aimed at the sensory trigeminal nerve - including the trigeminal sensory root, Gasserian ganglion and supra/infraorbital nerves - or the autonomic pathways involved in cluster headache - including the nervus intermedius, nervus petrosus major and sphenopalatine ganglion. Especially trigeminal destructive procedures are associated with potential serious long-term consequences such as anesthesia dolorosa, as well as corneal anesthesia and ulceration. The surgical management of refractory cluster headache is changing drastically with the advent of neuromodulatory techniques, such as occipital nerve stimulation and hypothalamic deep brain stimulation. These techniques were developed based on the physiology of the trigeminocervical complex and on evidence for a hypothalamic generator in cluster headache respectively. The potential therapeutic effect of each technique should be carefully balanced against known potential long-term consequences, knowing that long-term data on the rate of recurrence of cluster headache after a procedure are generally lacking. No conclusive recommendations can be formulated at present, but we will suggest some guidelines towards implementing surgical interventions for refractory cluster headache in clinical practice. We will briefly touch upon greater occipital nerve block as a transitional treatment. 


\section{Established Knowledge}

\section{A. Introduction}

There is no universally accepted definition of refractory cluster headache $(\mathrm{rCH})$ at present and there is no set of criteria in the International Classification of Headache Disorders second edition (ICHD-II). There is a great need to develop the concept, as a percentage of chronic cluster headache $(\mathrm{CH})$ patients and episodic $\mathrm{CH}$ patients with frequent cluster bouts are refractory to medical treatment indeed, or have contra-indications, intolerance and resistance to drugs used in $\mathrm{CH}$ prevention. It is estimated that drugs are ineffective in about 10 to $20 \%$ of chronic $\mathrm{CH}$ patients (May 2005), but we are lacking formal epidemiological data. For these patients surgical procedures are available, as a last resort when the pharmacological options have been fully exploited. However, with the recent surge of data on occipital nerve stimulation, one can envision that this minimally invasive technique may be used earlier in the course of the disorder if further controlled studies confirm the efficacy and safety.

The rationale for available surgical treatments in $\mathrm{rCH}$ is based on the three basic aspects of $\mathrm{CH}$ pathophysiology: strictly unilateral distribution head pain, cranial autonomic features and chronobiology pointing at the hypothalamus. Surgical approaches, including destructive procedures and neuromodulatory procedures are summarized in Table 1. Many of these techniques have been abandoned today. 
Table 1

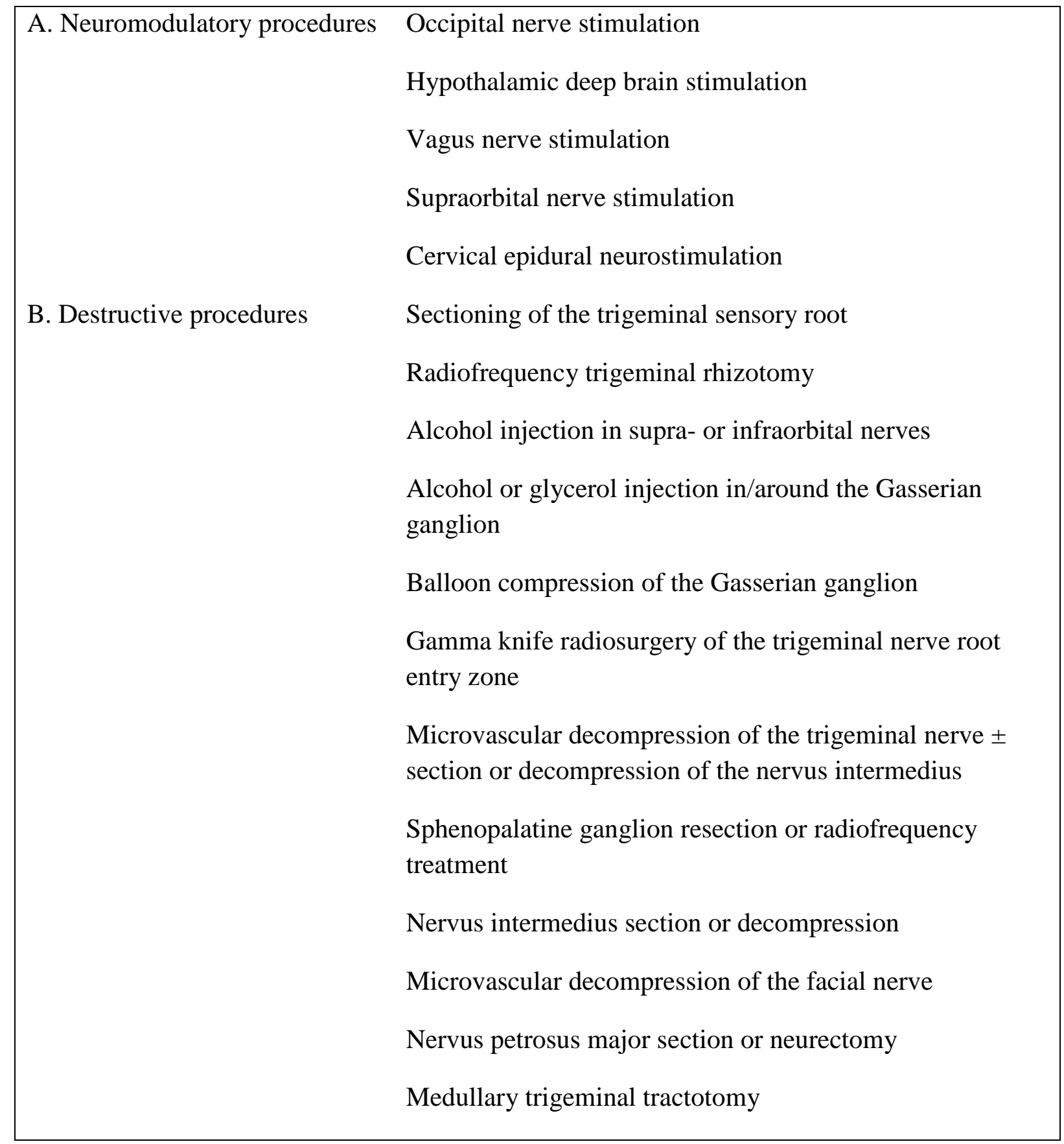

Legend table 1: Surgical procedures for refractory cluster headache. 
There are a few important aspects when considering and evaluating surgical procedures for $\mathrm{rCH}:$

1. It has been shown that a good proportion of chronic cluster patients eventually go into remission spontaneously (Manzoni et al. 1991). This is illustrated by 9 out of 12 cluster patients, that were chronic for at least 2 years and went into remission while on a waiting list for hypothalamic deep brain stimulation in the context of a clinical trial (Schoenen et al. 2005). Changes in drug therapy were only made in some of them.

2. Attacks may switch sides after an intervention even if the patient has always experienced strictly unilateral attacks (Jarrar et al. 2003; Magis et al. 2007).

3. There are well documented cases of persistence of $\mathrm{rCH}$ after complete trigeminal root section, indicating that $\mathrm{CH}$ may be generated primarily from within the brain (Matharu and Goadsby 2002).

4. Long-term follow-up of destructive procedures is generally limited, but recurrence of $\mathrm{CH}$ in responders may be seen in the short term (Morgenlander and Wilkins 1990).

5. Most studies on surgical interventions are retrospective and observational. There is only one randomized placebo-controlled double-blind trial in the domain of neuromodulation (Fontaine et al. 2010).

6. Because of the severity of the pain, the placebo response in $\mathrm{CH}$ has been considered to be small. However upon review of the available data, the placebo response appeared to be of the same magnitude as that seen in migraine studies (Nilsson Remahl et al. 2003).

7. Because of the unbearable nature of chronic $\mathrm{CH}$ higher percentages of adverse events and lower percentages of responders have been allowed to accept a therapy as worthwhile (Dodick 2005).

\section{B. Greater occipital nerve blockade}

The results of greater occipital nerve $(\mathrm{GON})$ block ipsilateral to the pain were first described in 1985 in CH (Anthony 1985). Some open label and uncontrolled studies (Peres et al. 2002; Afridi et al. 2006) and a double-blind placebo-controlled trial (Ambrosini et al. 2005) now support the efficacy of GON block. A mixture of the local anesthetic lidocaine and a corticosteroid, such as betamethasone (Ambrosini et al. 2005), triamcinolone (Peres et al. 2002) and methylprednisolone (Afridi et al. 2006), is generally injected. The efficacy of the injection does not seem to be related to the lidocaine in the solution, but rather to the 
corticosteroid (Anthony 1985; Ambrosini et al. 2005). Hence, the term 'block' is a bit confusing as none of the patients reported marked occipital numbness in the placebocontrolled study (Ambrosini et al. 2005). It is not ruled out that the (main) effect of the corticosteroid injection in the suboccipital region is systemic, although intramuscular injections were ineffective in one study (Anthony 1987) and higher doses are generally needed for systemic administration (Ambrosini et al. 2005). A double blind trial comparing suboccipital and intramuscular injections of the same mixture is awaited to further verify a specific effect. At present, GON block is an interesting option as a single suboccipital injection completely suppressed $\mathrm{CH}$ attacks in more than $80 \%$ of $\mathrm{CH}$ patients in the doubleblind placebo-controlled study, and the effect was maintained for at least 4 weeks in the majority of them (Ambrosini et al. 2005). As such, GON blockade is merely a transitional treatment to bridge time to a long-term treatment.

\section{Destructive procedures}

Destructive procedures have historically been the only long-term option. Sectioning of the sensory trigeminal root should however now be considered as a very last resort for a desperate patient indeed, as it is associated with significant and permanent long-term morbidity, including anesthesia dolorosa and corneal anesthesia (Jarrar et al. 2003). Strict ophthalmological follow-up is necessary to avoid corneal ulceration. Furthermore, the longterm success rate of sensory trigeminal root section is far from guaranteed (Morgenlander and Wilkins 1990; Matharu and Goadsby 2002) and CH attacks may develop on the contralateral side (Jarrar et al. 2003). Complete trigeminal sensory root sectioning seems to be more effective than partial sectioning (Kirkpatrick et al. 1993). Other destructive procedures targeting (part of) the trigeminal nerve include retrogasserian glycerol injection (Ekbom et al. 1987; Hassenbusch et al. 1991; Pieper et al. 2000), radiofrequency trigeminal rhizotomy (Onofrio and Campbell 1986; Mathew and Hurt 1988; Taha and Tew 1995), trigeminal ganglion balloon compression (Constantoyannis et al. 2008) and alcohol injections of the supra- and infraorbital nerves (Dodick 2005). Discouraging results have been reported with medullary trigeminal tractotomy (Sweet 1988). Percutaneous radiofrequency trigeminal rhizotomy at one point in time was the most frequently performed procedure (Campbell 2000), and is still performed in many centers today. However, it does not figure in a recent evidencebased clinical practice algorithm for interventional management of $\mathrm{CH}$ (van Kleef et al. 2009). 
Gamma knife radiosurgery of the trigeminal nerve root entry zone has been reported in 5 chronic $\mathrm{CH}$ patients with neglible short-term and long-term sequelae (Ford et al. 1998). Unfortunately later reports did not corroborate the initial enthusiasm as many failures were reported as well as sequelae (Donnet et al. 2005; McClelland et al. 2007). In a prospective open trial of gamma knife treatment for $\mathrm{rCH}$, a low rate of pain cessation and a significant number of trigeminal nerve injuries, including deafferentiation pain, were observed at one year follow-up (Donnet et al. 2005). The authors of the prospective trial judged the radiosurgery a less attractive procedure because of the low rate of pain cessation in conjunction with significant morbidity.

Microvascular decompression of the trigeminal nerve with or without microvascular decompression or sectioning of the nervus intermedius was reported to be effective in chronic $\mathrm{CH}$ in a single series of 28 patients treated between 1974 and 1996 and with an average follow-up of 5.3 years (Lovely et al. 1998). The rationale for the combined approach was to treat both the pain, mediated by the trigeminal system, as well as the autonomic symptoms, thought to be mediated by the nervus intermedius. There was no morbidity from nervus intermedius sectioning and there were no instances of trigeminal neuropathy. Complications included infection, cerebrospinal fluid leak and postoperative headache requiring a lumbar puncture. Substantial long-term relief was provided in almost half the patients as 9 patients had at least $90 \%$ improvement and 5 at least $50 \%$ improvement. These procedures carry the risk of cerebellopontine angle surgery and require an experienced neurosurgical team. Furthermore findings of vascular compression were consistent at operation, but could be detected with advanced MRI techniques nowadays. Further experience with this combined approach is needed (Dodick 2005).

Autonomic pathways have been interrupted specifically too to treat $\mathrm{rCH}$, especially cranial parasympathetic fibres, originating from the superior salivatory nucleus, and sequentially traversing the nervus intermedius (which leaves the brainstem as part of the facial nerve), nervus petrosus major and sphenopalatine ganglion to provide innervation to the lacrimal gland. Percutaneous radiofrequency ablation of the sphenopalatine ganglion is performed in many centers, but the evidence base is rather poor. The parasympathetic sphenopalatine ganglion is located in the sphenopalatine fossa, close to the maxillary nerve and the internal maxillary artery, and can be targeted via an infrazygomatic approach or via the lateral nasal wall (Felisati et al. 2006). In the most recent published series of 15 patients, the mean attack 
frequency improved from 17 attacks/week to 8 attacks per week at 18 months follow-up (Narouze et al. 2009). Two patients developed episodic CH on the contralateral side but reported complete relief of their usual unilateral cluster headaches. Only 3 patients remained headache free and off medications for the duration of follow-up (between 18 and 24 months). An earlier study reported on complete pain relief in 3 out of 10 chronic cluster patients after radiofrequency lesioning of the sphenopalatine ganglion, but no relief was found in 4 patients with an average follow-up of 24 months (Sanders and Zuurmond 1997). Another study with 20 patients reported on good results, which were always temporarily (Felisati et al. 2006). Radiofrequency lesioning of the sphenopalatine ganglion can result in postoperative epistaxis, cheek hemorrhage, a lesion of the maxillary nerve and hypesthesia of the palate (Sanders and Zuurmond 1997; Narouze et al. 2009). Total destruction of the sphenopalatine ganglion could result in eye dryness (Meyer et al. 1970), but the radiofrequency treatment now only aims at a partial lesion of the ganglion (van Kleef et al. 2009). Pulsed radiofrequency is perhaps safer, but data on its efficacy in $\mathrm{CH}$ are lacking at present. In a recent review, radiofrequency treatment of the sphenopalatine ganglion was put forward as the interventional treatment of choice for $\mathrm{rCH}$ (van Kleef et al. 2009). Small series exist on other procedures directed at the autonomic pathways, including nervus intermedius section (Rowed 1990), facial nerve decompression (Solomon and Apfelbaum 1986) and nervus petrosus major section (Denecke 1977).

\section{Neuromodulatory procedures}

There has been considerable progress in neurostimulation approaches, both central and peripheral, in the treatment of primary headache disorders, including chronic $\mathrm{CH}$ (Magis and Schoenen 2008; Bartsch et al. 2009).

Central neuromodulation emerged as a result of functional neuroimaging, revealing activation in the ipsilateral posteroinferior hypothalamus during spontaneous and nitroglycerin-induced CH attacks (May et al. 1998; Sprenger et al. 2004). The first case treated with hypothalamic Deep Brain Stimulation (DBS) was reported in 2001 in a chronic CH patient who had previously undergone ablative trigeminal surgery (Leone et al. 2001). Hypothalamic DBS has since been performed at several institutions and has been shown to be effective and relatively safe in the management of chronic rCH (Bartsch et al. 2009; Grover et al. 2009; Sillay et al. 2009). Nevertheless clear failures have been reported too (Pinsker et al. 2008). On review of 
the open label data in 2009, $36(71 \%)$ out of 55 patients $(71 \%)$ were improved with hypothalamic DBS, including 25 patients (46\%) that became completely headache free (Bartsch et al. 2009). A preliminary analysis indicates that hypothalamic DBS is associated with a marked reduction of direct costs of drug-resistant chronic $\mathrm{CH}$ (Leone et al. 2009). The assessment of efficacy of hypothalamic DBS for chronic $\mathrm{CH}$ was limited to open studies until 2009. However, in 2010 the first randomized placebo-controlled double-blind trial of unilateral hypothalamic DBS in 11 chronic $\mathrm{rCH}$ patients was published (Fontaine et al. 2010). During a randomized phase of 1 month active and sham stimulation were compared and no significant difference was observed between active and sham stimulation. The randomized phase was followed by a 1 year open phase during which every patient received effective hypothalamic DBS. At the end of the 1 year open phase, 6/11 had responded to chronic stimulation of which 3 were completely pain-free. Eventhough the randomized phase did not support the efficacy of hypothalamic DBS for chronic $\mathrm{CH}$, the open phase data corroborated previous open studies. This suggests hypothalamic DBS acts via slow neuromodulatory processes (Ambrosini and Schoenen 2010). In order to obtain level I evidence for hypothalamic DBS in chronic $\mathrm{CH}$, additional controlled studies with a longer randomized phase are required. Hypothalamic DBS is not devoid of potential serious adverse events. Infection, transient loss of consciousness, micturition syncopes, transient ischemic attack, asymptomatic third ventricular hemorrhage, panick attack and even death due to intracerebral haemorrhage along the lead tract have been reported (Franzini et al. 2003; Schoenen et al. 2005; Fontaine et al. 2010). Many authors advocate the use of ONS prior to hypothalamic DBS when considering a neuromodulation procedure (Ambrosini 2007; Leone et al. 2008; Bartsch et al. 2009; Burns et al. 2009). Criteria have been proposed to select chronic $\mathrm{CH}$ patients that are suitable candidates for DBS (Leone et al. 2004).

Occipital nerve stimulation (ONS) was originally described in the treatment of occipital neuralgia (Weiner and Reed 1999), but it is a promising modality of treatment for chronic $\mathrm{rCH}$ based on both retrospective and prospective data. Peripheral nerve stimulation is a minimally invasive and reversible procedure. The rationale to apply ONS in $\mathrm{CH}$ is based on the concept of a trigeminocervical complex (TCC). Physiological studies in animals have pointed at convergence of trigeminal (trigeminal nucleus caudalis) and upper cervical (dorsal horns C1-C3) nociceptive information, and thus a loss of spatial specificity at the level of the second order neurons of what is collectively called the TCC (Bartsch and Goadsby 2003). The concept of a TCC is furthermore supported by human experimental evidence (Piovesan et al. 
2001; Busch et al. 2006). This functional continuum between occipital and trigeminal nociceptive input is important to understand how occipital neurostimulation could be effective in $\mathrm{CH}$, characterized by activation of the trigeminovascular system. A stimulator is implanted under local or general anesthesia at the level of the occipitocervical junction, such that stimulation causes slight paresthesia in the distribution of the occipital nerves. The technique is however far from standardized as many technical variations have been described (Paemeleire and Bartsch 2010). In chronic $\mathrm{CH}$ results have been variable, as at least $50 \%$ improvement was noted in about $1 / 3$ and $2 / 3$ of patients respectively in the two largest case series, one prospective on 8 patients and one retrospective on 14 patients (Magis et al. 2007; Burns et al. 2009). The delay to clinical efficacy is variable and in the prospective study, a delay of 2 months or more between implantation and significant clinical improvement was noted, which suggests that ONS acts via slow neuromodulatory processes in chronic $\mathrm{CH}$ and argues against a 1 month trial period that is often part of the procedure and may be required for reimboursement (Magis et al. 2007). ONS is a safe technique and so far not a single neurological deficit has been reported with the technique. However, there is a consistent need for frequent reinterventions (including for battery replacement and lead migration) and some unpleasant local side effects may arise (including discomfort, shock like sensation, neck stiffness, muscle spasm and lead tip erosion). Some have opted for immediate bilateral ONS implantation after reports of contralateral development of cluster attacks in patients who described side locked attacks before implantation (Burns et al. 2009).

A beneficial effect of high cervical epidural neurostimulation has been reported in a single case of chronic $\mathrm{CH}$ (Wolter et al. 2008). A good result with vagus nerve stimulation was reported in 2 chronic $\mathrm{CH}$ patients (Mauskop 2005) and in 1 additional patient who had initially improved after hypothalamic DBS (Franzini et al. 2009). A beneficial outcome of supraorbital nerve stimulation has been reported in a single patient (Narouze and Kapural 2007). The numbers are too small to allow any conclusion. Whether these neurostimulation methods have a place in the management of chronic $\mathrm{rCH}$ patients remains to be determined (Magis and Schoenen 2008).

\section{E. State of the art}

GON blockade with (a mixture of lidocaine and) corticosteroid is an interesting transitional treatment as it may suppress $\mathrm{CH}$ attacks for a few weeks in the majority of $\mathrm{CH}$ patients. 
As the effectiveness of many surgical interventions, including radiofrequency treatment of the sphenopalatine ganglion, ONS and hypothalamic DBS, only stems from uncontrolled studies, no conclusive evidence is available yet. Recommendations should not be solely based on therapeutic effect. The potential effect of a technique should be closely balanced against the burden and risk of the procedure. The surgical management of $\mathrm{rCH}$ is changing rapidly with the development of neuromodulation techniques.

In 2006, the European Federation of Neurological Societies (EFNS) has published guidelines on the treatment of $\mathrm{CH}$, including general recommendations on surgical procedures (May et al. 2006). The EFNS warns for the lack of reliable long-term data on the outcome of surgical procedures, especially as some procedures may be associated with serious complications. The EFNS proposes that surgical procedures are not indicated in most $\mathrm{CH}$ patients, but that patients with intractable chronic $\mathrm{CH}$ should be referred to centres with expertise in both destructive and neuromodulatory procedures to be offered all reasonable alternatives before a definitive procedure is conducted.

Radiofrequency treatment of the sphenopalatine ganglion appears to be reasonably safe with open label evidence supporting its use, and has recently been suggested as a first line treatment (van Kleef et al. 2009), although some experts have almost abandoned destructive procedures in favor of neuromodulation techniques (Matharu and Goadsby 2008).

ONS has not achieved as high proportion of pain-free patients as DBS, but several centres now first offer the less invasive treatment of these two (Grover et al. 2009). The level of evidence supporting ONS is equal to that of radiofrequency treatment of the sphenopalatine ganglion according to a recent review (van Kleef et al. 2009). ONS is a safe technique but revisions are often necessary. The potential of ONS should be further explored in experienced centers, preferably in the context of clinical trials. Hypothalamic DBS should be left to experienced centers. A controlled trial of hypothalamic DBS with a longer blinded phase is needed to further support its usefulness.

Given the severity of $\mathrm{CH}$, which may drive patients to suicidal ideations (Rothrock 2006), more aggressive and destructive procedures may be opted for. Patients should however be fully informed about the potential long-term consequences.

Finally, local reimboursement issues and available expertise may dictate the surgical treatment strategy in $\mathrm{rCH}$, rather than the science supporting the available techniques. 


\section{Current Research}

At present the therapeutic potential, the mechanisms of action as well as the optimal technique of neurostimulation procedures is being further explored.

\section{Occipital nerve stimulation}

Most often electrodes typically used for spinal cord stimulation are employed for occipital nerve stimulation. Bilateral electrodes can be inserted through a single midline incision, and connected to an implantable impulse generator in the subclavicular, abdominal or gluteal area. Reinterventions are frequent and may be due to lead fracture, lead migration (which may occur in up to $100 \%$ of patients at three year follow-up, depending on the technique) and need for battery replacement (Schwedt et al. 2007; Bartsch et al. 2009). A recent development is the Bion device. It is a rechargeable mini-neurostimulator with a cylindrical shape, a length of $27 \mathrm{~mm}$ and $3 \mathrm{~mm}$ in diameter. It can easily be implanted adjacent to the greater occipital nerve. If bilateral ONS is required, a device must be implanted both on the left and on the right side (Trentman et al. 2009). Optimal stimulation parameters for ONS, such as pulse width, amplitude and frequency, are determined by trial and error, but systematic study has begun with the Bion device (Trentman et al. 2009).

\section{Hypothalamic DBS}

The hypothalamic target for DBS in chronic $\mathrm{CH}$ was chosen on the basis of neuroimaging studies revealing structural and functional abnormalities in the posterior part of the hypothalamus (Bartsch et al. 2009). The target reported by the Milan group in commissural coordinates is $2 \mathrm{~mm}$ lateral to the midline, $5 \mathrm{~mm}$ inferior to the axial plane containing anterior and posterior commissures, and $3 \mathrm{~mm}$ posterior to the midcommissural point (Franzini et al. 2003). It has been argued that this target is posterior to the hypothalamus or rather in the border zone between posterior hypothalamus, anterior periventricular gray matter and inferior thalamus (Sillay et al. 2009). Using probabilistic tractography, the functional connectivity of this target has been explored with highly consistent connections with the reticular nucleus and cerebellum (Owen et al. 2007). $\mathrm{H}_{2}{ }^{15} \mathrm{O}$-positron emission tomography data argue against an unspecific anti-nociceptive effect or pure inhibition of hypothalamic activity, and rather suggest modulation of the pain matrix (May 2008). 


\section{References}

Afridi SK, Shields KG, Bhola R and Goadsby PJ (2006) Greater occipital nerve injection in primary headache syndromes--prolonged effects from a single injection. Pain 122: 126-129

Ambrosini A (2007) Occipital nerve stimulation for intractable cluster headache. Lancet 369: 1063-1065

Ambrosini A, Schoenen J (2010) Commentary on Fontaine et al.: "Safety and efficacy of deep brain stimulation in refractory cluster headache: a randomized placebo-controlled double-blind trial followed by a 1-year open extension". J Headache Pain 11: 21-22

Ambrosini A, Vandenheede M, Rossi P, Aloj F, Sauli E, Pierelli F, Schoenen J (2005) Suboccipital injection with a mixture of rapid- and long-acting steroids in cluster headache: a double-blind placebo-controlled study. Pain 118: 92-96

Anthony M (1985) Arrest of attacks of cluster headache by local steroid injection of the occipital nerve. In: Rose FC (ed) Migraine: Clinical and Research Advances. Karger, London, pp 169-173

Anthony M (1987) The role of the occipital nerve in unilateral headache. In: Advances in Headache Research. Proceedings of the 6th International Migraine Symposium 1986. John Libbey \& Co Ltd, London, pp 257-262

Bartch T, Goadsby P J (2003) The trigeminocervical complex and migraine: current concepts and synthesis. Curr Pain Headache Rep 7: 371-376

Bartsch T, Paemeleire K, Goadsby P J (2009) Neurostimulation approaches to primary headache disorders. Curr Opin Neurol 22: 262-268

Burns B, Watkins L, Goadsby PJ (2009) Treatment of intractable chronic cluster headache by occipital nerve stimulation in 14 patients. Neurology 72: 341-345

Busch V, Jakob W, Juergens T, Schulte-Mattler W, Kaube H, May A (2006) Functional connectivity between trigeminal and occipital nerves revealed by occipital nerve blockade and nociceptive blink reflexes. Cephalalgia 26: 50-55

Campbell JK (2000). Surgical and ablative management of cluster headache. In: Olesen J, Goadsby PJ (eds) Cluster headache \& related conditions, Oxford University Press, Oxford, pp 264-270

Constantoyannis C, Kagadis G, Chroni E (2008) Percutaneous balloon compression for trigeminal neuralgias and autonomic cephalalgia. Headache 48: 130-134 
Denecke HJ (1977) [Greater petrosal nerve surgery in long-term cluster headache (author's transl)]. HNO 25: 48-50

Dodick DW (2005) Chronic cluster headache. In: Goadsby PJ, Silberstein SD, Dodick DW (eds) Chronic daily headache for clinicians, BC Decker Inc, London, pp 65-80

Donnet A, Valade D, Regis J (2005) Gamma knife treatment for refractory cluster headache: prospective open trial. J Neurol Neurosurg Psychiatry 76: 218-221

Ekbom K, Lindgren L, Nilsson BY, Hardebo JE, Waldenlind E (1987) Retro-Gasserian glycerol injection in the treatment of chronic cluster headache. Cephalalgia 7: 21-27

Felisati G, Arnone F, Lozza P, Leone M, Curone M, Bussone G (2006) Sphenopalatine endoscopic ganglion block: a revision of a traditional technique for cluster headache. Laryngoscope 116: 1447-1450

Fontaine D, LaMertens P, Blond S, Geraud G, Fabre N, Navez M, Lucas C, Dubois F, Gonfrier S, Paq zorthes Y, uis P, Lanteri-Minet M (2010) Safety and efficacy of deep brain stimulation in refractory cluster headache: a randomized placebo-controlled double-blind trial followed by a 1-year open extension. J Headache Pain 11: 23-31

Ford RG, Ford KT, Swaid S, Young P, Jennelle R (1998) Gamma knife treatment of refractory cluster headache. Headache 38: 3-9

Franzini A, Ferroli P, Leone M, Broggi G (2003) Stimulation of the posterior hypothalamus for treatment of chronic intractable cluster headaches: first reported series. Neurosurgery 52: 1095-1099.

Franzini A, Messina G, Leone M, Cecchini AP, Broggi G, Bussone G (2009) Feasibility of simultaneous vagal nerve and deep brain stimulation in chronic cluster headache: case report and considerations. Neurol Sci 30 Suppl 1: S137-139

Grover PJ, Pereira EA, Green AL, Brittain JS, Owen SL, Schweder P, Kringelbach ML, Davies PT, Aziz TZ (2009) Deep brain stimulation for cluster headache. J Clin Neurosci 16: 861-866

Hassenbusch SJ, Kunkel RS, Kosmorsky GS, Covington EC, Pillay PK (1991) Trigeminal cisternal injection of glycerol for treatment of chronic intractable cluster headaches. Neurosurgery 29: 504-508

Jarrar RG, Black DF, Dodick DW, Davis DH (2003) Outcome of trigeminal nerve section in the treatment of chronic cluster headache. Neurology 60: 1360-1362

Kirkpatrick PJ, O'Brien MD, MacCabe JJ (1993) Trigeminal nerve section for chronic migrainous neuralgia. Br J Neurosurg 7: 483-490 
Leone M, Franzini A, Bussone G (2001) Stereotactic stimulation of posterior hypothalamic gray matter in a patient with intractable cluster headache. N Engl J Med 345: 14281429

Leone M, Franzini A, Cecchini AP, Mea E, Broggi G, Bussone G (2009) Costs of hypothalamic stimulation in chronic drug-resistant cluster headache: preliminary data. Neurol Sci 30 Suppl 1: S43-47

Leone M, May A, Franzini A, Broggi G, Dodick D, Rapoport A, Goadsby PJ, Schoenen J, Bonavita V, Bussone G (2004) Deep brain stimulation for intractable chronic cluster headache: proposals for patient selection. Cephalalgia 24: 934-937

Leone M, Proietti Cecchini A, Franzini A, Broggi G, Cortelli P, Montagna P, May A, Juergens T, Cordella R, Carella F, Bussone G (2008) Lessons from 8 years' experience of hypothalamic stimulation in cluster headache. Cephalalgia 28: 787-797

Lovely TJ, Kotsiakis X, Jannetta PJ (1998) The surgical management of chronic cluster headache. Headache 38: 590-594

Magis D, Allena M, Bolla M, De Pasqua V, Remacle JM, Schoenen J (2007) Occipital nerve stimulation for drug-resistant chronic cluster headache: a prospective pilot study. Lancet Neurol 6: 314-321

Magis D, Schoenen J (2008) Neurostimulation in chronic cluster headache. Curr Pain Headache Rep 12: 145-153

Manzoni GC, Micieli G, Granella F, Tassorelli C, Zanferrari C, Cacallini (1991) A Cluster headache--course over ten years in 189 patients. Cephalalgia 11: 169-174

Matharu M, Goadsby PJ (2008) Trigeminal autonomic cephalalgias: diagnosis and management. In: Silberstein SD, Lipton RB, Dodick DW (eds) Wolff's headache. Oxford University Press, Oxford, pp 379-430

Matharu MS, Goadsby PJ (2002) Persistence of attacks of cluster headache after trigeminal nerve root section. Brain 125: 976-984

Mathew NT, Hurt W (1988) Percutaneous radiofrequency trigeminal gangliorhizolysis in intractable cluster headache. Headache 28: 328-331

Mauskop A (2005) Vagus nerve stimulation relieves chronic refractory migraine and cluster headaches. Cephalalgia 25: 82-86

May A (2005) Cluster headache: pathogenesis, diagnosis, and management. Lancet 366: 843855

May A (2008) Hypothalamic deep-brain stimulation: target and potential mechanism for the treatment of cluster headache. Cephalalgia 28: 799-803 
May A, Bahra A, Buchel C, Frackowiak RS, Goadsby PJ (1998) Hypothalamic activation in cluster headache attacks. Lancet 352: 275-278

May A, Leone M, Afra J, Linde M, Sandor PS, Evers S (2006) EFNS guidelines on the treatment of cluster headache and other trigeminal-autonomic cephalalgias. Eur J Neurol 3: 1066-1077

McClelland S 3rd, Barnett GH, Neyman G, Suh JH (2007) Repeat trigeminal nerve radiosurgery for refractory cluster headache fails to provide long-term pain relief. Headache 47: 298-300

Meyer JS, Binns PM, Ericsson AD, Vulpe M (1970) Sphenopalatine gangionectomy for cluster headache. Arch Otolaryngol 92: 475-484

Morgenlander JC, Wilkins RH (1990) Surgical treatment of cluster headache. J Neurosurg 72: $866-871$

Narouze S, Kapural L, Casanova J, Mekhail N (2009) Sphenopalatine ganglion radiofrequency ablation for the management of chronic cluster headache. Headache 49: $571-577$

Narouze SN, Kapural L (2007) Supraorbital nerve electric stimulation for the treatment of intractable chronic cluster headache: a case report. Headache 47: 1100-1102

Nilsson Remahl AI, Laudon Meyer E, Cordonnier C, Goadsby PJ (2003) Placebo response in cluster headache trials: a review. Cephalalgia 23: 504-510

Onofrio BM, Campbell JK (1986) Surgical treatment of chronic cluster headache. Mayo Clin Proc 61: 537-544

Owen SL, Green AL, Davies P, Stein JF, Aziz TZ, Behrens T, Voets NL, Johansen-Berg H (2007) Connectivity of an effective hypothalamic surgical target for cluster headache. J Clin Neurosci 14: 955-960

Paemeleire K, Bartsch T (2010) Occipital nerve stimulation for headache disorders. Neurotherapeutics: in press

Peres MF, Stiles MA, Siow HC, Rozen TD, Young WB, Silberstein SD (2002) Greater occipital nerve blockade for cluster headache. Cephalalgia 22: 520-522

Pieper DR, Dickerson J, Hassenbusch SJ (2000) Percutaneous retrogasserian glycerol rhizolysis for treatment of chronic intractable cluster headaches: long-term results. Neurosurgery 46: 363-368

Pinsker MO, Bartsch T, Falk D, Volkmann J, Herzog J, Steigerwald F, Diener HC, Deuschl G, Mehdorn M (2008) Failure of deep brain stimulation of the posterior inferior 
hypothalamus in chronic cluster headache - report of two cases and review of the literature. Zentralbl Neurochir 69: 76-79

Piovesan EJ, Kowacs PA, Tatsui CE, Lange MC, Ribas LC, Wenneck LC (2001) Referred pain after painful stimulation of the greater occipital nerve in humans: evidence of convergence of cervical afferences on trigeminal nuclei. Cephalalgia 21: 107-109

Rothrock J (2006) Cluster: a potentially lethal headache disorder. Headache 46: 327

Rowed DW (1990) Chronic cluster headache managed by nervus intermedius section. Headache 30: 401-406

Sanders M, Zuurmond WW (1997) Efficacy of sphenopalatine ganglion blockade in 66 patients suffering from cluster headache: a 12- to 70-month follow-up evaluation. J Neurosurg 87: 876-880

Schoenen J, Di Clemente L, Vandenheede M, Fumal A, De Pasqua V, Mouchamps M, Remacle JM, de Noordhout AM (2005) Hypothalamic stimulation in chronic cluster headache: a pilot study of efficacy and mode of action. Brain 128: 940-947

Schwedt TJ, Dodick DW, Hentz J, Trentman TL, Zimmerman RS (2007) Occipital nerve stimulation for chronic headache--long-term safety and efficacy. Cephalalgia 27: 153157

Sillay KA, Sani S, Starr PA (2009) Deep brain stimulation for medically intractable cluster headache. Neurobiol Dis: in press

Solomon S, Apfelbaum RI (1986) Surgical decompression of the facial nerve in the treatment of chronic cluster headache. Arch Neurol 43: 479-482

Sprenger T, Boecker H, Tolle TR, Bussone G, May A, Leone M (2004) Specific

hypothalamic activation during a spontaneous cluster headache attack. Neurology 62: $516-517$

Sweet WH (1988) Surgical treatment of chronic cluster headache. Headache 28: 669-670

Taha JM, Tew JM Jr (1995) Long-term results of radiofrequency rhizotomy in the treatment of cluster headache. Headache 35: 193-196

Trentman TL, Rosenfeld DM, Vargas BB, Schwedt TJ, Zimmerman RS, Dodick DW (2009) Greater occipital nerve stimulation via the Bion microstimulator: implantation technique and stimulation parameters. Clinical trial: NCT00205894. Pain Physician 12: 621-628

van Kleef M, Lataster A, Narouze S, Mekhail N, Geurts JW, van Zundert J (2009) Evidencebased interventional pain medicine according to clinical diagnoses. 2. Cluster headache. Pain Pract 9: 435-442 
Weiner R, Reed K (1999) Peripheral Neurostimulation for Control of Intractable Occipital Neuralgia. Neuromodulation 2: 217-222

Wolter T, Kaube H, Mohadjer M (2008) High cervical epidural neurostimulation for cluster headache: case report and review of the literature. Cephalalgia 28: 1091-1094 